\title{
Desafios enfrentados pelos professores no cenário pandêmico e no pós pandemia: professores e os desafios encontrados em tempo de pandemia
}

\author{
Challenges faced by teachers in the pandemic and post-pandemic scenario: teachers and the \\ challenges encountered in time of a pandemic \\ Desafíos de los docentes en el escenario pandémico y pospandémico: los profesores y los desafíos \\ enfrentados en tiempo de pandemia
}

Recebido: 09/11/2021 | Revisado: 14/11/2021 | Aceito: 15/11/2021 | Publicado: 16/11/2021

\author{
Dayane Rodrigues dos Santos \\ ORCID: https://orcid.org/0000-0002-3382-3965 \\ Faculdade Guaraí, Brasil \\ E-mail: rodriguesdayane675@gmail.com \\ Keila Fernandes Oliveira \\ ORCID: https://orcid.org/0000-0003-2906-4158 \\ Faculdade Guaraí, Brasil \\ E-mail: keilafernandes577@gmail.com \\ Zilma Cardoso Barros Soares \\ ORCID: https://orcid.org/0000-0002-2812-7121 \\ Faculdade Guaraí, Brasil \\ E-mail: zilma_pedagoga@hotmail.com
}

\begin{abstract}
Resumo
O presente artigo tem como tema geral os desafios encontrados pelos professores em tempos de pandemia. Os obstáculos que a população encontrou por consequências da pandemia do novo Coronavírus afetou diversos setores da sociedade em especial a educação, mais de dois terços de estudantes no mundo sofreram com danos ao seu processo de ensino aprendizagem, com altos níveis de desigualdades nesse setor, a falta de acesso e apoio para com os estudantes e principalmente os professores foram sem precedentes. Diante do problema, objetivou-se analisar quais os desafios encontrados pelos professores em tempos de pandemia? Este trabalho trata-se de uma pesquisa com base teórica sendo fundamentada em artigos, revistas online e teses. Para que com esses recentes dados de pesquisas esse trabalho se torne relevante em discutir e entender de forma geral esses novos desafios na educação básica em tempos de pandemia.
\end{abstract}

Palavras-chave: Educação; Desafios; Pandemia; Professores.

\begin{abstract}
This article has as its general theme the challenges faced by teachers in times of pandemic. The obstacles that the population encountered as a result of the new Coronavirus pandemic affected various sectors of society, especially education, more than two thirds of students in the world suffered damage to their teaching-learning process, with high levels of inequalities in this sector, lack of access and support for students and especially teachers was unprecedented. Faced with the problem, the objective was to analyze what are the challenges faced by teachers in times of pandemic? This work is a theoretically based research based on articles, online journals and theses. So that with these recent research data, this work becomes relevant in discussing and understanding in general these new challenges in basic education in times of pandemic.
\end{abstract}

Keywords: Education; Challenges; Pandemic; Teachers.

\section{Resumen}

Este artículo tiene como tema general los desafíos que enfrentan los docentes en tiempos de pandemia. Los obstáculos que encontró la población como consecuencia de la nueva pandemia de Coronavirus afectaron a diversos sectores de la sociedad, especialmente a la educación, más de dos tercios de los estudiantes en el mundo sufrieron daños en su proceso de enseñanza-aprendizaje, con altos niveles de desigualdad en este sector, La falta de acceso y apoyo para los estudiantes y especialmente los profesores no tiene precedentes. Ante el problema, el objetivo fue analizar ¿cuáles son los desafíos que enfrentan los docentes en tiempos de pandemia? Este trabajo es una investigación de base teórica basada en artículos, revistas en línea y tesis. De manera que con estos datos de investigaciones recientes, este trabajo cobra relevancia en la discusión y comprensión en general de estos nuevos desafíos en la educación básica en tiempos de pandemia.

Palabras clave: Educación; Desafíos; Pandemia; Maestros. 


\section{Introdução}

A Covid-19 é uma doença provocada pelo novo coronavírus SARS-CoV-2. O vírus surgiu na China em dezembro de 2019 e espalhou-se rapidamente pelo mundo todo, provocando os primeiros casos no Brasil em dezembro de 2020 (BRASIL, 2020). Para maior eficiência no combate a disseminação da Covid-19, a OMS recomendou que os países fizessem isolamento social, que as pessoas evitassem aglomerações e que os hábitos pessoais de higiene fossem intensificados (WHO, 2020). Por isso, foi determinada a suspensão das aulas e o fechamento de diversas escolas e universidades como medida preventiva de contaminação e propagação do vírus. O início da pandemia do novo coronavírus (SARS-CoV-2) trouxe diferentes impactos no mundo todo, principalmente porque não havia planos estratégicos para o enfrentamento de uma pandemia desse tipo (Freitas et al., 2020). Entretanto, levando em consideração à importância da educação e as consequências negativas que essa medida traria na sociedade, fez-se necessário repensar formas de atender a todos com educação de qualidade, de maneira igualitária e segura à preservação da vida.

Para os professores que se encontravam isolados em suas residências esse momento trouxe grande tensão à respeito das metodologias usuais e suas práticas de ensino. Levando em consideração que muitos educadores não possuíam preparação para a inclusão de novas tecnologias por não terem tido a formação que contemplasse tecnologias digitais, sendo preciso recorrer a atualizações e capacitações que assegurem a qualidade do ensino (Gonzalez et al., 2020; Kim et al., 2020). Além disso, como afirmam Carmo e Selles (2018), estando inseridos em diferentes contextos, esses docentes exercem diversas práticas para obtenção de conhecimentos escolares que atendem aos saberes dos alunos e à demanda da escola. Como uma alternativa facilitadora de acesso à educação para dar continuidade ao ano letivo surgiram as atividades educacionais remotas emergenciais autorizadas pela Portaria n³45/2020 do Ministério da Educação.

A pandemia do novo coronavírus trouxe atrelado às suas incertezas, um cenário inédito na educação mundial, com grandes impactos na educação brasileira. Os professores tiveram que lidar com uma série de desafios, mesmo estando confinados em suas residências se sentiram na obrigação de se reinventarem e buscar alternativas viáveis para que a educação não continuasse paralisada e fosse negligenciada.

Portanto, esse trabalho de pesquisa tem como objetivo fornecer um respaldo para auxiliar os novos profissionais da área da educação sobre os principais desafios encontrados na docência diante desse cenário inédito e fomentar a análise e reflexão de melhorias que atendam às necessidades observadas. E a partir disso pretende-se identificar os tipos de recursos utilizados para a participação dos alunos em tempo de pandemia; relacionar os diferentes tipos de acesso para o ensino e aprendizagem dos alunos no ensino remoto e documentar o processo de transição de um modelo tradicional de ensino para um ensino totalmente feito de forma remota mediado pela tecnologia.

Por isso a necessidade de os professores proporcionar atividades cada vez mais favoráveis a promoção de aprendizagem, possibilitando o desenvolvimento do conhecimento com avaliações centradas nesse processo, com conteúdo cada vez diversificados, apropriados das propostas pedagógicas de cada instituição no exercício da prática. Como informa Oliveira (2020, p.39), "nesse novo ambiente de aprendizagem, o professor precisa ir além, motivar, aguçar a curiosidade, instigar a pesquisa, provocar a reflexão, o desenvolvimento do pensamento crítico"

Compreendendo que praticamente todo o processo de ensino aprendizado é relevante para o desenvolvimento da criança, a profissão de professor envolve muito na relação interpessoal e acolhedor, atualmente o mundo se encontra totalmente globalizado, tudo se conecta em tempo real e comunidade são criadas em questões de minutos, as fronteiras físicas se tornam meras relevâncias, através de um click viaja-se o mundo. Com a proibição da circulação de pessoas, o distanciamento social, instituições de ensino fechados, uma reforma foi criada dentro dos planejamentos escolares para que houvesse um bom desenvolvimento das habilidades estudantis dentro no ambiente familiar, isso fez com que o professor ficasse inteirado, conectado, presente profundamente sem intervalos de tempo e espaço, trazendo consigo novos horizontes além de alunos e 
familiares nesse novo modelo de ensino aprendizado.

Com a inviável realização das aulas presenciais entre professores e alunos, devido ao isolamento, o ensino remoto surge como uma alternativa de diminuição dos impactos negativos durante o processo de ensino aprendizagem, então os professores, pais e alunos passaram para o ensino a distância sem nenhuma preparação. Tendo em vista a necessidade de uma criação para a "educação a distância", sendo uma educação formal, a personificação do professor, o dever de responder positivamente e rapidamente para adapte-se ou mudar suas práticas e trazendo um conjunto de transformações fundamentais no desenvolvimento do trabalho dentro da didática atual de ensino.

Segundo Silveira (2020, p. 38) o ensino remoto, vendo sendo aplicado de forma emergencial devido à pandemia da COVID-19, sendo essa uma situação inesperada, ou seja, os PPP's das instituições não foram construídos para dar suportar uma modalidade de $\mathrm{EaD}$, com finalidades de estruturação no currículo e os processos de ensino e de aprendizagem em uma modalidade diferenciada como tal. Deste modo, os professores apenas estão usando meios como TDICs, e mantendo as mesmas metodologias de ensino que eram utilizadas no ensino presencial e na transmissão de conhecimentos, por meio de aulas expositivas e exercícios para fixação de conteúdo. Nesse contexto, os professores relataram diversos desafios relacionados à educação a distância.

Durante uma pandemia, por exemplo: adaptabilidade e flexibilidade relacionadas a novos métodos de ensino aprendizagem e o uso ferramentas tecnológicas de ensino, gerando muita insegurança, dúvidas e sobrecarga de trabalho a motivação do aluno e participação no ambiente virtual as dificuldades enfrentadas pelos alunos também afetarão a relação de ensino. Compreendendo todo esse processo de mudança ocorrida no setor educacional essa pesquisa se torna cada vez mais relevante para o conhecimento futuro.

\section{Metodologia}

As metodologias ativas farão ainda mais parte das aulas e também será necessário o reforço escolar para equalizar a aprendizagem e assegurar igualdade e equidade de oportunidades aos alunos, possibilitando o sequenciamento de atividades realizadas durante o período de isolamento social (Gafarolo, 2020). O isolamento social provocou uma situação de privação em diversos aspectos, como aprendizagens cognitivas, convivência afetivo-social etc.

A metodologia usada no projeto é bibliográfica, realizada em material publicado em livros e na web. Portanto, o mesmo se dá a partir do levantamento de referenciais teóricos já publicados. O início do estudo foi executado com a formação teórica sobre o tema, iniciando-se por uma pesquisa bibliográfica e análise preliminar sobre o tema da pesquisa. Foram expostas algumas metodologias de análise e melhoria sobre o tema em questão e buscou-se então os critérios de utilização e suas ferramentas para a utilização em sala de aula e as melhorias durante esse processo. Verificou-se a adequada metodologia realmente poderia ser utilizada durante o processo de ensino-aprendizagem e quais os benefícios. E por último fez -se então o estudo de caso com a aplicação de uma metodologia escolhida e analise.

Compreendendo que uma investigação bibliográfica é de suma importância no âmbito acadêmico, para que possa ser diferenciada chegando ao ponto onde o leitor possa refletir: até que ponto aquela teoria mobilizada colabora ou não no ato de tornar o objeto de pesquisa complexo, por fim, esperamos que esse trabalho sirva de colaboração ao docente na utilização do lúdico dentro da escola básica, com a finalidade de contribuir para que suas aulas sejam, cada vez mais, atrativas e eficazes.

O trabalho foi construído de forma estruturada dentro das normas para atingir o objetivo proposto. Suas sessões são referentes aos objetivos colocados. A primeira parte com bases teóricas dos artigos, as metodologias aplicadas e como foram as formações dos professores para os ensinos remotos. Posteriormente, identificar os tipos de recursos utilizados para a participação dos alunos em tempo de pandemia relacionando os diferentes tipos de acesso para o ensino e aprendizagem dos alunos no ensino remoto finalizando com as maiores dificuldades dos professores. 


\section{Resultados e Discussão}

\subsection{Principais desafios enfrentados pelos professores}

Devido ao distanciamento social, medida imposta de prevenção à pandemia do novo coronavírus, os professores foram obrigados a traçar novas estratégias pedagógicas que melhor se adequassem na nova realidade acadêmica. Na pesquisa de Godoi et al, (2020) os docentes relataram que este processo acarretou sentimentos de incertezas, angústia, questionamentos e sobrecarga de trabalho.

Para que os professores fossem preparados para esse novo desafio na educação, muitas escolas e instituições de ensino deram início aos cursos on-line, lives (transmissões ao vivo pela internet), videoconferências, treinamentos virtuais, porém, em alguns casos, não houve nem formações, apenas a imposição ao uso de ferramentas digitais para essa finalidade, sem as orientações necessárias para a preparação dos docentes (Joye et al, 2020). Observar, processar, compreender as mudanças que têm ocorrido diante do cenário atual apresenta-se como mais um desafio ao professor que busca se reinventar e se atualizar em um limite de tempo muito curto e urgente. Outros desafios que surgiram foram: o suporte tecnológico e acesso à internet aos alunos para participar das atividades remotas e as normatizações dos procedimentos e atitudes (Valente et al., 2020).

Doenças, como a síndrome do esgotamento profissional, têm acometido alguns docentes devido ao não cumprimento dos objetivos impostos pela instituição somado ao estresse provocado pelas pressões provocados pela utilização de tecnologias, aulas a serem gravadas, incertezas, ansiedade, depressão (Silva, et al., 2020; Araújo et al., 2020). Segundo Shaw (2020) esses docentes encontram-se inseridos em um ambiente favorável ao adoecimento mental em consequência dos impactos gerados pela Covid-19, seja pelas taxas de mortalidade divulgadas em telejornais como também pela sobrecarga advinda da cobrança do uso de tecnologias pelas instituições de ensino acrescido a vida conjugal, materna/paterna, doméstica e entre tantas outras responsabilidades que lhe são atribuídas.

Ainda de acordo com uma pesquisa feita em março de 2020 docentes vinculados a rede privada de ensino aparentavam ter mais preparação com a interação remota em comparação com professores da rede pública; a rede privada de ensino parecia dispor de mais apoio à distância aos discentes (Instituto Península, 2020). Em um trabalho feito por Borba et al (2020) foram apontadas como maiores dificuldades pelos professores nessa modalidade de ensino: a conexão instável e lenta à internet, excesso de trabalho e questionamentos acerca das melhores estratégias metodológicas para o ensino de Ciências e Biologia de maneira remota. Além disso vale ressaltar que o trabalho docente homeoffice está atrelado a dinâmica doméstica, onde muitas vezes, o computador, principal ferramenta de trabalho, é utilizado pela família o que pode causar transtorno durante o expediente do trabalho do educador.

Ludovico et al, (2020) aponta ainda outras dificuldades enfrentadas no trabalho docente como: estabelecer quais os recursos a serem utilizados, as formas de comunicação, determinar quanto tempo levará cada atividade, a idade dos alunos, definir abordar novos conteúdos ou revisar o que já foi abordado. Outro ponto importante é o aumento relativo de recursos e custos que o professor acaba acarretando na docência por homeoffice, como gastos com ar condicionado, computador, internet, energia, mobiliário, telefone, etc.

Dessa maneira, observa-se a "uberização" do trabalho realizado pelo professor na modalidade remota, pois como afirma Silva (2019) o trabalho na empresa Uber exige que o trabalhador seja responsável pela mercadoria que vai vender e pelo serviço que será prestado. Esse cenário reflete o aumento da carga horária de trabalho e a transferência de gastos e riscos para os docentes do país (Barbosa, Ferreira \& Kato, 2020). A realidade torna-se ainda mais difícil para as mulheres docentes, pois sobre elas recaem maior carga de stress com os filhos e outros familiares na residência (Santos, 2020). Devido ao machismo ainda vigente, as tarefas domésticas não são divididas, e assim, as mulheres se desdobram para lidar com os afazeres de casa e as múltiplas atribuições do trabalho. 
Os docentes também expuseram a dificuldade que possuem em incentivar e engajar os alunos nesse novo jeito de ensino mediado pelas tecnologias digitais, tão diferente do convívio presencial da sala de aula ao qual estavam habituados (Godoi et al, 2020). A ausência da interação presencial, o diálogo, o convívio têm um grande impacto no processo de ensino/aprendizagem, bem como um meio de avaliação do envolvimento dos alunos, pois como destaca Paulo Freire (1977), a educação é baseada em comunicação, onde é possível estabelecer um entre os interlocutores uma busca pela significação dos significados.

A pandemia do novo coronavírus trouxe atrelado às suas incertezas, um cenário inédito na educação mundial, com grandes impactos na educação brasileira. Os professores tiveram que lidar com uma série de desafios, mesmo estando confinados em suas residências se sentiram na obrigação de se reinventarem e buscar alternativas viáveis para que a educação não continuasse paralisada e fosse negligenciada. Em contrapartida, esses desafios proporcionaram variadas aprendizagens profissionais, como por exemplo: adequação, descobertas, experiências e uso de ferramentas e metodologias novas; novas formas de interagir com seus alunos, conhecer melhor os discentes e suas necessidades, o apoio a colegas de profissão, entre outros (Godoi et al, 2020).

Por isso, vale ressaltar, a importância da pandemia da Covid-19 como propulsor do desenvolvimento profissional dos docentes, favorecendo novas aprendizagens profissionais e à inclusão das tecnologias digitais no sistema pedagógico, levando em consideração que essas ferramentas e esse aprendizagem serão essenciais sendo indispensáveis para o futuro do ensino no país.

\subsection{Desafios no uso de ferramentas digitais no ensino remoto}

O ambiente físico da sala de aula habitual, constituído de quatro paredes, lousa e carteiras, teve que ser emergencialmente e subitamente substituído pelas plataformas digitais para que a educação não continuasse paralisada juntamente com outras atividades e interações sociais durante a pandemia da Covid-19. Consequentemente, o professor acaba sendo incumbido das funções de criador de recursos digitais, motivador, mediador de grupos e interações online e de avaliador de aprendizagens (Moreira; Henriques; Barros, 2020). E assim, como afirmam Almeida e Valente (2012), adaptar-se ao uso das tecnologias para fins pedagógicos vai muito além das mídias em si, abrange também informações, linguagens, relações culturais, espaços e tempos.

Embora, as ferramentas tecnológicas educacionais já atendessem as demandas sociais educativas antes mesmo do distanciamento social ser empregado pelas instituições de ensino, boa parte do ensino e da aprendizagem ainda ocorriam de forma presencial, o que representa uma boa parcela de profissionais da educação e alunos carentes de treinamento adequado, e cheios de incertezas e dúvidas sobre a viabilidade do ensino à distância obrigatório (Carneiro et al., 2020). Além disso é necessário assegurar aos alunos que não têm acesso, dispositivos e conectividade que permitam o acesso às aulas e demais atividades promovendo a aprendizagem mútua e colaborativa.

As escolas precisaram se organizar para ministrarem as aulas com uso das tecnologias digitais, gerando assim um novo modelo de ensino. De acordo com Moreira e Schlemmer (2020, p.9) no ensino remoto

[...] o ensino presencial físico (mesmos cursos, currículo, metodologias e práticas pedagógicas) é transposto para os meios digitais, em rede. O processo é centrado no conteúdo, que é ministrado pelo mesmo professor da aula presencial física. Embora haja um distanciamento geográfico, privilegia-se o compartilhamento de um mesmo tempo, ou seja, a aula ocorre num tempo síncrono, seguindo princípios do ensino presencial. A comunicação é predominantemente bidirecional, do tipo um para muitos, no qual o professor protagoniza videoaula ou realiza uma aula expositiva por meio de sistemas de web conferência. Dessa forma, a presença física do professor e do aluno no espaço da sala de aula geográfica são substituídas por uma presença digital numa sala de aula digital. No ensino remoto ou aula remota o foco está nas informações e nas formas de transmissão dessas informações.

Uma sala de aula virtual requer uma boa estrutura de comunicação para que os discentes se sintam motivados e 
conectados e envolvidos no processo de aprendizagem. Assim como afirmam os autores Moreira, Ferreira e Almeida (2013), uma sala de aula virtual vazia trata-se de uma vivência insignificante para o aluno, uma sala sem presença social e cognitiva torna-se inevitavelmente um espaço "sem vida".

Para Rodrigues Junior (2014, p. 2): nos tempos atuais há disponíveis diversas mídias educacionais, o fator desafiante em questão é ter a capacidade para usá-las de maneira eficiente e tornar possível que elas contribuam definitivamente para o aperfeiçoamento das práticas pedagógicas. É perceptível que o destaque nesse processo não é "o quê", mas o "como fazer", realizar e construir. Nesse aspecto, corroborando com Moran (2018), as metodologias ativas surgem para mostrar o papel protagonista que o aluno deve assumir na construção do seu próprio aprendizado, aliando-se ao uso das tecnologias, apesar do entendimento da essencialidade do uso das mesmas, de que há uma resistência por parte, até então, do âmbito escolar, como aponta Sahb (2016, p. 6):

A falta de recursos, de infraestrutura, o despreparo dos professores e da equipe pedagógica, os materiais que chegam à escola por imposição e não por escolha dos professores, a quantidade de material inadequada ao porte do colégio, estão entre os principais. Tais fatores interferem consideravelmente na disposição dos educadores para a utilização das inovações, como se fosse possível ficar indiferente à influência que elas exercem sobre as pessoas.

Dentre as ferramentas digitais que estão sendo adotadas pelos professores estão os "fóruns" que permitem a comunicação assíncrona sem necessitar da confluência do professor e dos alunos no espaço e no tempo, gerando um modelo educativo mais flexível, característica necessária diante do cenário pandêmico. Entretanto, vale ressaltar que esta ferramenta precisa estar bem organizada e estruturada e que todos os usuários sigam as regras operacionais (Goulão, 2012). Já o WhatsApp tem sido a ferramenta de comunicação instantânea mais adotada pelos professores, por permitir a rápida troca de mensagens, arquivos diversos e ser mais acessível à maioria dos alunos que já estavam habituados a essa ferramenta no cotidiano antes da pandemia.

Outro recurso bastante explorado pelos professores, principalmente para utilização de vídeos, é o Youtube. Esta plataforma possibilita ao usuário publicar, visualizar e compartilhar vídeos de sua própria autoria ou de outras, inclusive é possível encontrar nessa plataforma diversos conteúdos educativos e até aulas completas de ensino superior de instituições de ensino de prestígios como Yale, Stanford, MIT, The Open University, entre outras (Moreira; Henriques; Barros, 2020). Outras principais plataformas e recursos digitais educacionais são Google, Google Classroon, Google Meet, Google Drive, Google Hangout, Facebook, Instagram, Microsoft Teams, Perfect Education, Moodle, Zoom, entre outros.

Moreira \& Monteiro (2015) ressaltam que para que os recursos digitais sejam utilizados de forma eficiente sob uma perspectiva pedagógica é necessário conhecer os softwares, já que a simples utilização de interfaces digitais não assegura por si só, bons resultados nas práticas educativas. Seja de forma síncrona ou assíncrona, o docente continua tendo um papel essencial para orientar a aprendizagem dos discentes além de subsidiar condições para a efetiva colaboração e aprendizagem para os professores ofertando acesso e aos recursos e plataformas digitais (Carneiro et al., 2020).

\subsection{Retomada das aulas presenciais e perspectivas dos professores para o ensino pós pandemia}

Com a aprovação da Anvisa para uso emergencial das vacinas Oxford/AstraZeneca e da Coronavac no dia 17 de janeiro de 2021 o Brasil deu início às campanhas de vacinação pelo país inteiro, priorizando primeiramente grupos de idosos de acordo com faixas etárias decrescentes (ANVISA, 2021). Com o avanço da vacinação e ampliação do acesso à população em geral, aos poucos as aulas puderam ser retomadas gradativamente de forma presencial. Isto posto fica o seguinte questionamento: o que esperar da educação pós-pandemia?

Almeida et al. (2021) afirmam que a educação no Brasil não será mais a mesma, já que os professores tiveram que se 
reinventar e modificar suas estratégias pedagógicas, isso abriu mais espaço para discussões acerca do uso de tecnologias no ensino, aulas interativas, metodologias ativas que são mais atrativas e motivadoras para os discentes. A perspectiva é que o uso das ferramentas pedagógicas digitais seja incorporado na rotina pedagógica das escolas de diversas formas e utilidades para proporcionar a aprendizagem.

Tavares e Sousa (2021) apostam no ensino híbrido como uma modalidade de ensino que permanecerá após a pandemia, destacando a necessidade de uma formação docente mais abrangente que busque melhor desenvolver práticas educacionais mediadas pelas tecnologias e ambientes virtuais de aprendizagem. Conforme afirma Sousa (2018, p. 33), a mudança esperada nessas práticas, em tempos e espaços de estimulação, consiste na maneira como o professor irá utilizar sua criatividade no desenvolvimento de suas aulas, em favor de quem ele se dispõe ensinar-aprender.

Sob essa perspectiva, Gatti (2020) expõe que será necessário um esforço de gestão para a preparação dos profissionais educacionais para o retorno e acolhimento dos alunos, destacando que tanto professores como alunos podem ter tido experiência com a Covid-19 e até mesmo perdas de pessoas importantes. Tendo isso em questão, vê-se a carência de um preparo psicológico de todos os envolvidos com a escolarização, criando propostas e ações que sirvam de acolhimento as necessidades ou dificuldades percebidas que afetam a aprendizagem no retorno.

A angústia provocada de forma repentina pela preservação da vida gerou grandes impactos. E a educação está intimamente ligada à preservação da vida em todos os seus aspectos, tanto culturais, como ambientais, sociais, científicos, entre outros, de maneira a proporcionar a formação integral com base em conhecimentos (Gatti, 2020). Adquirir conhecimentos relacionados com valores de vida é o vetor saudável que deve ser mantido para o novo cenário em questão. Barbosa, Viegas e Batista (2020) acrescentam que os profissionais da educação no atual momento vivenciam novas experiências em suas rotinas laborais, somadas com mais complexidade que o habitual que demandam trabalho mental mais completo para melhor eficiência da prestação de serviço. Diante disso, tanto como docentes como discentes, podem apresentar ou identificar certas dificuldades em todo o processo de retomada das aulas $100 \%$ presenciais.

\section{Considerações Finais}

Foi de grande aprendizado lembrando que a presente pesquisa permitiu atingir o seu objetivo principal na medida em que analisou em profundidade as diversas facetas das dificuldades encontradas em tempos de pandemia pelos professores, evidenciando novas fronteiras de pesquisas futuras mais específicas. A pesquisa para a realização do trabalho permitiu a abertura de um leque de pensamentos inovadores ora havia momentos que esquecemos da realização do trabalho e pensamos mesmo que estávamos dentro das instituições de ensino como professores e enfrentando seus desafios constantes.

Acreditando que o ensino remoto preconiza a transmissão em tempo real das aulas. Se faz necessário a interação dos professores com o aluno quase em tempo real mesmo que nos modelos remotos. Sabendo ainda da necessidade de equipamentos de qualidades tanto para os professores quanto para os estudantes em nossa pesquisa a maior dificuldade foi a falta de recursos e formação apropriada durante todo esse processo, professores sem equipamentos e alunos sem essa rede de apoio.

A educação é uma poderosa ferramenta para mudar o mundo. É por intermédio dela, que é possível formar cidadãos mais críticos, fomentar a criação de mais oportunidades de emprego e melhoria na sua própria qualidade de vida. A importância de aprender para si mesmo é compartilhar os conhecimentos com os outros. A utilização de equipamentos como computadores conectados à internet e as diversas ferramentas disponíveis, que inclusive já se encontram presentes e indispensáveis nas atividades mais corriqueiras da sociedade em geral, é uma ótima opção para prender a atenção dos alunos. 


\section{Referências}

Almeida, E. G. et al. (2021). Ensino remoto e tecnologia: uma nova postura docente na educação pós-pandemia.

Almeida, M. E. B., Valente, J. A. (2012). Integração currículo e tecnologias e a produção de narrativas digitais. Currículo sem fronteiras, $12(3)$, 57-82.

ANVISA - Agência Nacional de Vigilância Sanitária. Anvisa aprova por unanimidade uso emergencial das vacinas. Ministério da Saúde, 17 de janeiro de 2021. https://www.gov.br/anvisa/pt-br/assuntos/noticias-anvisa/2021/anvisa-aprova-por-unanimidade-uso-emergencial-das-vacinas.

Araújo, F. J. O., et al. (2020). Impact of Sars-Cov-2 and its Reverberation in Global Higher Education and Mental Health. Psychiatry Research, $288,112977$.

Barbosa, A. T, Ferreira, G. L., \& Kato, D. S. (2020). O ensino remoto emergencial de Ciências e Biologia em tempos de pandemia: com a palavra as professoras da Regional 4 da Sbenbio (MG/GO/TO/DF). Revista de Ensino de Biologia da SBEnBio, 379-399.

Barbosa, A. M., Viegas, M. A. S., \& Batista, R. L. N. F. F. (2020). Aulas presenciais em tempos de pandemia: relatos de experiências de professores do nível superior sobre as aulas remotas. Revista Augustus, 25(51), 255-280.

Borba, R. C. N. et al. Percepções docentes e práticas de ensino de ciências e biologia na pandemia: uma investigação da Regional 2 da SBEnBio. Revista de Ensino de Biologia da SBEnBio, 153-171.

Brasil. Medida Provisória $n^{\circ}$ 934, de $1^{\circ}$ de abril de 2020. Estabelece normas excepcionais sobre o ano letivo da educação básica e do ensino superior decorrentes das medidas para enfrentamento da situação de emergência de saúde pública de que trata a Lei no 13.979 , de 6 de fevereiro de 2020 . Diário Oficial da União Seção 1 - Edição Extra - A - 1/4/2020, Página 1 (Publicação Original). 2020.

Brasil. Portaria $\mathrm{N}^{\circ} 343$, de 17 de março de 2020. Dispõe sobre a substituição das aulas presenciais por aulas em meios digitais enquanto durar a situação de pandemia do Novo Coronavírus - COVID-19. D.O.U. 18/03/2020. https://www.in.gov.br/en/web/dou/-/portaria-n-343-de-17-de-marco-de-2020-248564376

Freitas, A. R. R., Napimoga, M., \& Donalisio, M. R. (2020). Análise da gravidade da pandemia de Covid-19. Epidemiologia e Serviços de Saúde, 29 , e2020119.

Garofalo, Débora. O que esperar da educação pós pandemia? https://www.uol.com.br/ecoa/colunas/debora-garofalo/2020/05/13/o-que-esperar-daeducacao-pospandemia.htm.

Gatti, B. A. (2020). Possível reconfiguração dos modelos educacionais pós-pandemia. Estudos Avançados, 34, 29-41

Godoi, M. et al. (2020). O ensino remoto durante a pandemia de covid-19: desafios, aprendizagens e expectativas dos professores universitários de Educação Física. Research, Society and Development, 9(10), e4309108734.

Histórico Da Pandemia De Covid-19, OPAS/OMS e COVID-19, c2021, Página inicial. https://www.paho.org/pt/covid19/historico-da-pandemia-covid-19.

Joye, C. R., Moreira, M. M., Rocha, S. S. D. (2020). Educação a Distância ou Atividade Educacional Remota Emergencial: em busca do elo perdido da educação escolar em tempos de COVID-19. Research, Society and Development, 9(7), e521974299-e521974299.

Kim, S. et al. (2020). School Opening Delay Effect on Transmission Dynamics of Coronavirus Disease 2019 in Korea: Based on Mathematical Modeling and Simulation Study. Journal of Korean Medical Science, 35(13).

Ludovico, F. M. et al. (2020). COVID-19: desafios dos docentes na linha de frente da educação. Interfaces Científicas. Aracaju, $10(1), 58-74$.

Moreira, J. A., Henriques, S., \& Barros, D. M. V. (2020). Transitando de um ensino remoto emergencial para uma educação digital em rede, em tempos de pandemia. Dialogia, 351-364.

Moreira, J. A., \& Schlemmer, E. (2020). Por um novo conceito e paradigma de educação digital onlife. Revista UFG, 20.

Oliveira. S. F. (2020). Pedagogos e professores em tempos de pandemia. Pedagogia em Ação, 13(1). 